\title{
Effects of Traffic and Road Factors on Motorcycling Safety Perception.
}

\begin{abstract}
In Malaysia and other developing Asian countries, the over-representation of the motorcycle population in mixed traffic results in a high number of motorcyclist casualties and fatalities. As a result, by providing a safer environment for motorcycling, the key problem of road accidents would be minimised. Therefore, this study aims to examine the effects of vehicle speed, traffic volume and lane width on mixed traffic conditions. Each of the 60 motorcyclists who took part in this study watched 12 video clips and saw six photographs of road scenes recorded from a number of sites, and rated their perceived safety related to the three variables. This study found that the perceived safety of motorcycling is associated with these three factors $(\mathrm{p}<0.01)$ and motorcycling safety would decrease under higher vehicle speed, heavier traffic volume and narrower lane width. Segregating motorcycles from mixed traffic is one engineering option to address motorcycling safety.
\end{abstract}

Keyword: Traffic engineering; Transport planning; Safety \& hazards 